\title{
Leaching of Al-Based Polygrain Quasicrystalline and Related Crystalline Surfaces
}

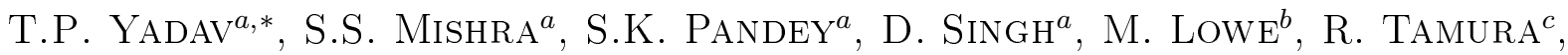 \\ N.K. Mukhopadhyay ${ }^{d}$, O.N. SRivastava ${ }^{a}$, R. MCGRATH $^{b}$, And H.R. Sharma ${ }^{b}$ \\ ${ }^{a}$ Hydrogen Energy Centre, Department of Physics (Centre of Advance Studies), \\ ${ }^{b}$ Surface Science Research Centre and Department of Physics, The University of Liverpool, Liverpool, L69 3BX, UK \\ ${ }^{c}$ Department of Materials Science and Technology, Tokyo University of Science, Noda 278-8510, Japan \\ ${ }^{d}$ Department of Metallurgical Engineering, Indian Institute of Technology, \\ Banaras Hindu University, Varanasi, 221005, India
}

\begin{abstract}
In the present investigation, we have studied leaching on polygrain Al-based quasicrystalline $\left(i\right.$ - $\left.\mathrm{Al}_{63} \mathrm{Cu}_{25} \mathrm{Fe}_{12}\right)$ as well as crystalline ( $B 2$ phase; $\mathrm{Al}_{55} \mathrm{Cu}_{30} \mathrm{Fe}_{15}$ ) alloy surfaces using a 10 mole $\mathrm{NaOH}$ solution. The surface was leached at varying times from 30 min to $8 \mathrm{~h}$ and subsequently characterized by X-ray diffraction, scanning electron microscopy, transmission electron microscopy and energy dispersive X-ray analysis. Leaching of the samples for 30 min generated a homogeneous layer. However further leaching for 1-8 h yielded nano-size particles on the surface. Spherical microstructure has been observed on the $\mathrm{Al}-\mathrm{Cu}-\mathrm{Fe}$ crystalline surface whereas on the quasicrystalline surface a petal-like microstructure appeared. The implications of the evolution of different microstructures in the context of structure, stability and activity are discussed. The results are compared with the microstructure of leached polygrained samples containing a mixture of different surface orientations.
\end{abstract}

DOI: 10.12693/APhysPolA.126.629

PACS: 61.44.Br; 81.16.Hc; 61.66.Dk; 68.37.Hk

\section{Introduction}

The discovery of a quasicrystal (QC) in a rapidlyquenched $\mathrm{Al}-\mathrm{Mn}$ alloy unveiled the existence of a completely different state of ordered solids [1]. After intensive investigations on their physical and mechanical properties, much interest nowadays is focused on finding practical applications for these materials [2-3]. Although, quasicrystalline materials are extremely brittle at room temperature [4], numerous studies have been undertaken to discover useful properties for their potential applications [5-8]. It is known that quasicrystals have some favorable properties, such as low adhesion behavior, high hardness, low friction coefficient, high wear resistance, low thermal conductivity and a compatible thermal expansion coefficient, indicating that these materials have potential for use in manufacturing technology [9]. One of the potential fields of the application of quasicrystalline materials is catalysis [10-13]. Since quasicrystals are equilibrium phases and are stable up to high temperature, they have the potential to be used as a catalyst at high temperature [14]. A powder of the thermally stable icosahedral (i) $\mathrm{Al}-\mathrm{Cu}-\mathrm{Fe}$ quasicrystal leached with $\mathrm{NaOH}$ aqueous solutions shows excellent activity for steam reforming of methanol [15-17]. The leaching treatments yielded $\mathrm{Cu}$ and $\mathrm{Fe}$ nanoparticles on top of the quasicrystalline surface. These nanoparticles

\footnotetext{
*corresponding author; e-mail: yadavtp@gmail.com
}

are believed to be responsible for catalytic behaviour. The dispersed Fe species in the homogeneous leached layer enhances the catalytic activity and suppresses the aggregation of $\mathrm{Cu}$ and is predominantly controlled by the dissolution rate of $\mathrm{Al}$ upon leaching [18]. The catalytic behavior of $\mathrm{QC}$ and related crystalline materials has been compared. QC catalyst has a higher catalytic activity and durability than the related crystalline catalysts [18]. Recently, the excellent performance of the QC catalyst has been described in terms of a composite structure with fine $\mathrm{Cu}$ nanoparticles dispersed in a $(\mathrm{Fe}, \mathrm{Al})_{3} \mathrm{O}_{4}$ matrix which was generated by a leaching treatment and calcination at $600^{\circ} \mathrm{C}$ in air [19]. In this case, the $\mathrm{Cu}_{x} \mathrm{Fe}_{3-x-y} \mathrm{Al}_{y} \mathrm{O}_{4}$ spinel structure decomposed into a composite structure with fine $\mathrm{Cu}$ nanoparticles dispersed in a $(\mathrm{Fe}, \mathrm{Al})_{3} \mathrm{O}_{4}$ matrix [20]. Recently, we have performed the leaching experiment on the well-orientated single grain fivefold $(i)-\mathrm{Al}-\mathrm{Cu}-\mathrm{Fe}$ and tenfold $(d)-\mathrm{Al}-\mathrm{Ni}-$ Co quasicrystalline surface [21]. The role played by the supporting quasicrystal and the dispersed metal $\mathrm{Cu} / \mathrm{Fe}$ nanoparticle ratio in the catalytic activity is not yet fully understood and the optimization of the catalytic activity is currently limited to heuristic approaches.

In the present work, we have investigated the leaching effect on two alloys: polygrain $(i)-\mathrm{Al}_{65} \mathrm{Cu}_{25} \mathrm{Fe}_{12}$ and crystalline (B2)- $\mathrm{Al}_{55} \mathrm{Cu}_{30} \mathrm{Fe}_{15}$.

\section{Experimental details}

\subsection{Synthesis}

Alloys of composition $\mathrm{Al}_{63} \mathrm{Cu}_{25} \mathrm{Fe}_{12}$, and $\mathrm{Al}_{55} \mathrm{Cu}_{30} \mathrm{Fe}_{15}$ were prepared by melting high purity $\mathrm{Al}, \mathrm{Cu}$ and $\mathrm{Fe}$ 
$(\mathrm{Al}=99.96 \%, \mathrm{Cu}=99.98 \%, \mathrm{Fe}=99.99 \%)$ metals in an induction furnace, in the presence of a dry argon atmosphere. The ingots formed were re-melted four times to ensure better homogeneity. The samples were cleaned by mechanical polishing using $\mathrm{Al}_{2} \mathrm{O}_{3}$ powder of $1 \mu \mathrm{m}$ size and subsequently washed in an ultrasonic bath with methanol for $15 \mathrm{~min}$. The leaching of the surfaces of the (i) $-\mathrm{Al}_{63} \mathrm{Cu}_{25} \mathrm{Fe}_{12}$ and (B2)- $\mathrm{Al}_{55} \mathrm{Cu}_{30} \mathrm{Fe}_{15}$ alloys was done by using a $10 \mathrm{~mol}$ concentration of $\mathrm{NaOH}$ aqueous solution. $\mathrm{NaOH}$ drops were placed on the clean $\mathrm{QC}$ and $B 2$ alloy surfaces by burette for $0.5-8 \mathrm{~h}$ at room temperature. The $\mathrm{NaOH}$ leached surfaces were thoroughly washed 4-5 times with methanol and distilled water in an ultrasonic bath until no trace of alkali was detected. This was confirmed through preliminary energy dispersive Xray analysis. After each leaching experiment and subsequent characterization, the samples were re-prepared for each leaching experiments.

\subsection{Characterizations}

The as-grown (i)- $\mathrm{Al}_{63} \mathrm{Cu}_{25} \mathrm{Fe}_{12}$ and (B2)$\mathrm{Al}_{55} \mathrm{Cu}_{30} \mathrm{Fe}_{15}$ alloys, before and after leaching, were characterized by powder X-ray diffraction (XRD) employing $\mathrm{Cu} K_{\alpha}$ radiation $(\lambda=1.5402 \AA)$ using X'Pert PRO (PANalytical). The characterization of the entire leached surface was done by using scanning electron microscope (SEM) FEI-QUANTA-200. Transmission electron microscopy (TEM) using FEI-TECNAI 20G ${ }^{2}$ was used for microstructural and structural characterization with an operating voltage at $200 \mathrm{kV}$. Energy-dispersive X-ray analysis (EDX) attached with FEI-TECNAI $20 \mathrm{G}^{2}$ electron microscope was employed for the compositional analysis.

\section{Results and discussion}

The first assessment of the effects of leaching on (i) $-\mathrm{Al}_{63} \mathrm{Cu}_{25} \mathrm{Fe}_{12}$ and (B2)- $\mathrm{Al}_{55} \mathrm{Cu}_{30} \mathrm{Fe}_{15}$ alloy surfaces was undertaken using SEM. Figure 1 shows SEM images of the leached surfaces of $(i)-\mathrm{Al}_{63} \mathrm{Cu}_{25} \mathrm{Fe}_{12}$ and (B2)$\mathrm{Al}_{55} \mathrm{Cu}_{30} \mathrm{Fe}_{15}$ alloys at different leaching times. In the case of $(i)-\mathrm{Al}_{63} \mathrm{Cu}_{25} \mathrm{Fe}_{12}$ surface, after $1 \mathrm{~h}$ the surface has been leached in depth (Fig. 1a) near the grain boundary and outlining the columnar structure which results in the formation of sub-micrometer porosity on the surface. For (B2)- $\mathrm{Al}_{55} \mathrm{Cu}_{30} \mathrm{Fe}_{15}$ the surface looks more porous (Fig. 1(e)). For further leaching times i.e. 2, 4, and $8 \mathrm{~h}$, tiny particles are observed on both $(i)-\mathrm{Al}_{63} \mathrm{Cu}_{25} \mathrm{Fe}_{12}$ and $(B 2)-\mathrm{Al}_{55} \mathrm{Cu}_{30} \mathrm{Fe}_{15}$ which was confirmed using high magnification SEM investigation (1b-d \& f-h). It was found that the density of the particles is much higher on the QC leached surface. The corresponding EDX spectra show that these particles are composed of $\mathrm{Cu}$ and $\mathrm{Fe}$. These particles are in good shape when leached for 2 and $4 \mathrm{~h}$; while further leaching for $8 \mathrm{~h}$, the particles become rougher. The appearance of such roughness may be due to the reaction of these particles with $\mathrm{NaOH}$ during the longer leaching time. This change in the morphology indicates that $\mathrm{Al}$ had been removed from the alloy surface during initial leaching leading to precipitation of $\mathrm{Cu} / \mathrm{Fe}$ on the surface. Upon further leaching the $\mathrm{Cu} / \mathrm{Fe}$ precipitates also react. The sizes of the precipitates are in the nano-meter range and bigger on the $B 2$ surface compared to the QC surface.
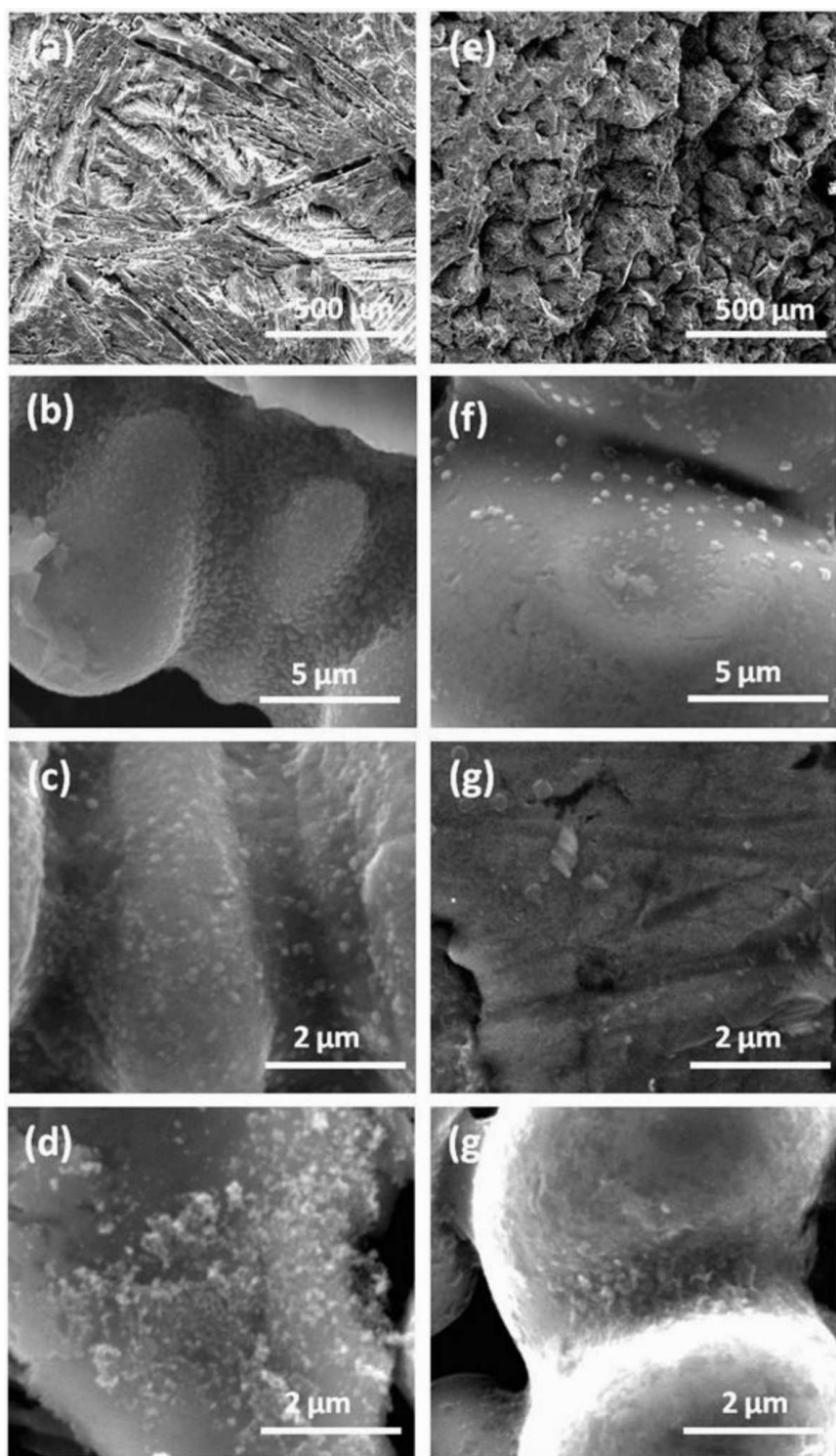

Fig. 1. SEM images of leached surface at different leaching time for $(i)-\mathrm{Al}_{63} \mathrm{Cu}_{25} \mathrm{Fe}_{12}$ (a) $1 \mathrm{~h}$, (b) $2 \mathrm{~h}$, (c) $4 \mathrm{~h},(\mathrm{~d}) 8 \mathrm{~h}$ and for $(B 2)-\mathrm{Al}_{55} \mathrm{Cu}_{30} \mathrm{Fe}_{15}$ (e) $1 \mathrm{~h}$, (f) $2 \mathrm{~h}$, (g) $4 \mathrm{~h},(\mathrm{~h}) 8 \mathrm{~h}$ respectively.

Figure $2 \mathrm{a}$ and $\mathrm{b}$ shows XRD patterns of $\mathrm{Al}_{63} \mathrm{Cu}_{25} \mathrm{Fe}_{12}$ quasicrystal annealed at $800^{\circ} \mathrm{C}$ for $10 \mathrm{~h}$ and subsequently leached in $10 \mathrm{~mol} \mathrm{NaOH}$ aqueous solution at room temperature for $8 \mathrm{~h}(\mathrm{~b})$. The X-ray diffraction peaks for the annealed sample can be assigned using the six-value index system proposed for the icosahedral phase allowing the identification of single quasicrystalline phase and indicating the homogeneity of the alloy. Extra diffraction peaks from $\mathrm{Cu}$ and $\mathrm{Fe}$ (Fig. 1b) are observed after leaching 


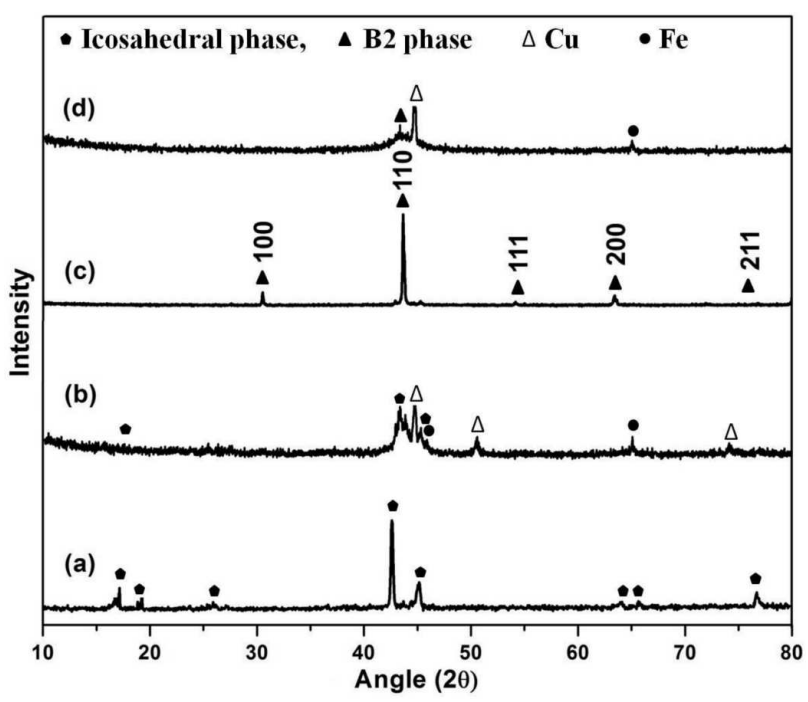

Fig. 2. (a) XRD patterns of the $\mathrm{Al}_{63} \mathrm{Cu}_{25} \mathrm{Fe}_{12}$ quasicrystal annealed at $800^{\circ} \mathrm{C}$ for $10 \mathrm{~h}$, and subsequently leached in $10 \mathrm{~mol} \mathrm{NaOH}$ aqueous solution at room temperature for $8 \mathrm{~h}$ (b), (c) XRD patterns of the (B2)$\mathrm{Al}_{55} \mathrm{Cu}_{30} \mathrm{Fe}_{15}$ alloy obtained after annealing at $800^{\circ} \mathrm{C}$ for $10 \mathrm{~h}$ and subsequently leached in $10 \mathrm{~mol} \mathrm{NaOH}$ aqueous solution at room temperature for $8 \mathrm{~h}$ (d).

treatment in $\mathrm{NaOH}$ solution. The use of the Voigt function for the analysis of the integral widths of broadened $\mathrm{X}$-ray diffraction line profiles allows rapid determination of crystallite size and strain. The size of the $\mathrm{Cu}$ particles was found to be $\approx 12 \mathrm{~nm}$ based on line broadening of the XRD peaks [22]. Figure $2 \mathrm{c}$ and d shows the XRD patterns for the (B2)- $\mathrm{Al}_{55} \mathrm{Cu}_{30} \mathrm{Fe}_{15}$ alloy obtained after annealing at $800^{\circ} \mathrm{C}$ for $10 \mathrm{~h}$ and subsequently leached in 10 mole $\mathrm{NaOH}$ aqueous solution at room temperature for 8 h. $B 2$ phase obtained from the as-cast ingot material was indexed with lattice parameter $a=2.91 \AA$. It can be seen that after leaching treatment for $8 \mathrm{~h}$, the (110) peak of the $B 2$ phase becomes broader and an intense peak of $\mathrm{Cu}$ and Fe was observed (Fig. 2d). These effects may be attributed to the leaching effect and the precipitation of nanoparticles. The size of the $\mathrm{Cu}$ and Fe particles was found to be $\approx 16 \mathrm{~nm}$ based on the line broadening of the XRD peaks.

In order to explore the microstructure of all the samples, TEM studies of the as-cast as well as leached (i) $-\mathrm{Al}_{63} \mathrm{Cu}_{25} \mathrm{Fe}_{12}$ and $(B 2)-\mathrm{Al}_{55} \mathrm{Cu}_{30} \mathrm{Fe}_{15}$ alloys were carried out. Figure 3 shows representative microstructure of the $8 \mathrm{~h}$ leached $(i)-\mathrm{Al}_{63} \mathrm{Cu}_{25} \mathrm{Fe}_{12}$ alloy. Nano-size grains can be seen in the microstructure around equiaxed grains of micron size (region $i$ ). The electron diffraction pattern taken from the region labelled $i$ shows a QC pattern along a twofold axis, typically observed in quasicrystals with icosahedral symmetry. The sharp diffraction spots arrayed in a non-periodic way indicate quasiperiodic structure (Fig. $3 \mathrm{~b}$ ). Electron diffraction from region $L$ shows the presence of spotty rings due to nanograin microstruc-

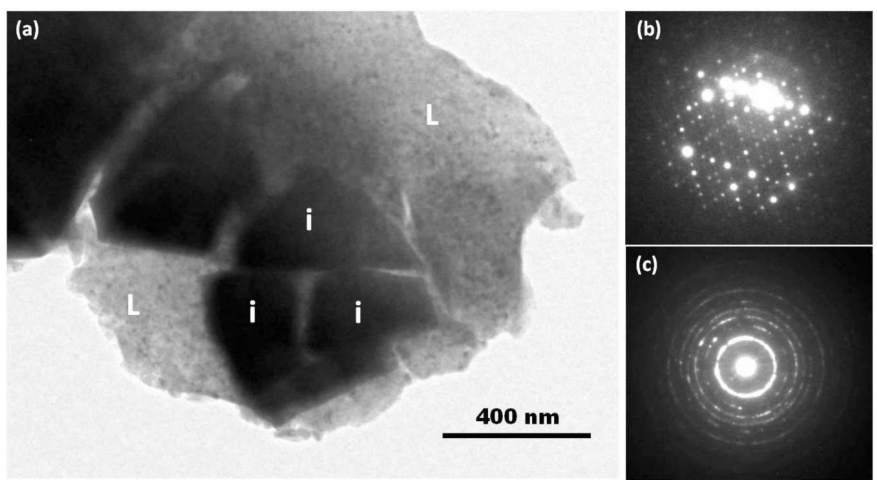

Fig. 3. (a) TEM microstructure of the $8 \mathrm{~h}$ leached $(i)$ $\mathrm{Al}_{63} \mathrm{Cu}_{25} \mathrm{Fe}_{12}$ alloy, (b) SAD pattern taken from region $i$ and (c) SAD pattern from region $L$.

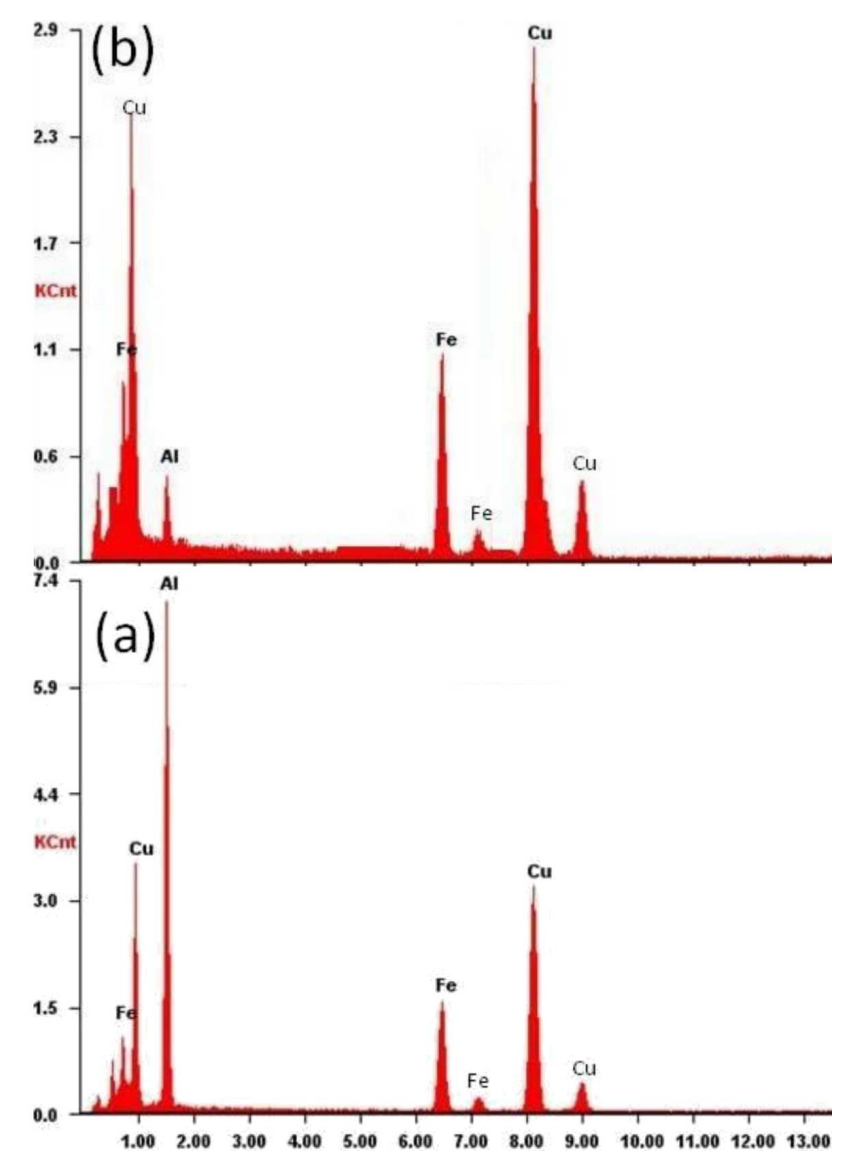

Fig. 4. The EDX spectra taken from both regions i.e. $i$ (a) and $L(\mathrm{~b})$.

ture (Fig. 3c). This pattern has been commonly observed in all leached samples. EDX (Fig. 4) was taken from both regions ( $i$ and $L$ ) which confirms that $\mathrm{Cu}$ is 25 at.\% and $\mathrm{Fe}$ is 20 at.\% from the $i$-region whereas the corresponding values are 60 at.\% and 30 at.\% from region $L$. This indicates that $\mathrm{Al}$ is dissolved during leaching and the proportion of $\mathrm{Cu}$ and $\mathrm{Fe}$ increases correspondingly. 
At the beginning of the leaching process i.e. below $0.5 \mathrm{~h}$, the dissolution of $\mathrm{Al}$ and precipitation of $\mathrm{Cu}$ and $\mathrm{Fe}$ is very slow; however, it increases after $1 \mathrm{~h}$ of leaching.

\section{Conclusions}

The leaching of polygrain $(i)-\mathrm{Al}_{63} \mathrm{Cu}_{25} \mathrm{Fe}_{12}$ and (B2)$\mathrm{Al}_{55} \mathrm{Cu}_{30} \mathrm{Fe}_{15}$ surfaces have been carried out for different time i.e. $1-8 \mathrm{~h}$ with $10 \mathrm{~mol} \mathrm{NaOH}$ aqueous solution. On the leached surface of the QC phase, nanoparticles of transition metals ( $\mathrm{Cu}$ and $\mathrm{Fe}$ ) were found. Results on the chemical composition measured by EDX analyses indicate a significant removal of Al. The catalytic properties of the leached surface require further investigation.

\section{Acknowledgments}

T.P.Y. thanks the Department of Science and Technology (DST) for BOYACAST fellowship during which period a part of the work was completed. The financial support received from DST and Ministry of New and Renewable Energy, India (Mission Mode Hydrogen Storage Project) is gratefully acknowledged.

\section{References}

[1] D. Shechtman, I. Blech, D. Gratias, J.W. Cahn, Phys. Rev. Lett. 53, 1951 (1984).

[2] J.M. Dubois, Isr. J. Chem. 51, 1168 (2011).

[3] J. M. Dubois, Useful Quasicrystals, World Scientific, Singapore 2005.

[4] U. Köster, H. Liebertz, W. Liu, Mater. Sci. Eng. A 181-182, 777 (1994).

[5] J.M. Dubois, P. Weinland, French patent No. 8810559 (1988).
[6] T.P. Yadav, D. Singh, R.S. Tiwari, O.N. Srivastava, Mat. Lett. 80, 5 (2012).

[7] M. Sales, A. Merstallinger, P. Brunet, M.C. de Weerd, V. Khare, G. Traxler, J.M. Dubois, Philos. Mag. 86, 965 (2006).

[8] S. Kenzari, D. Bonina, J. M. Dubois, V. Fournée, Mater. Des. 35, 691 (2012).

[9] S.B. Biner, D.J. Sordelet, B.K. Lograsso, I.E. Anderson, US Patent No. 5851317 (1998).

[10] A.P. Tsai, M. Yoshimura, Appl. Catal. A 214, 237 (2001).

[11] M. Yoshimura, A.P. Tsai, J. Alloys Comp. 342, 451 (2002).

[12] B. Phung Ngoc, C. Geantet, M. Aouine, G. Bergeret, S. Raffy, S. Marlin, Int. J. Hydrog. Energy 33, 1000 (2008).

[13] K. Nosaki, T. Masumoto, A. Inoue, T. Yamaguchi, United state Patent No. 5800638 (1998).

[14] C. J. Jenks, P. A. Thiel, J. Mol. Catal. A: Chem. 131, 301 (1998).

[15] S. Kameoka, T. Tanabe, A.P. Tsai, Catal. Today 93-95, 23 (2004)

[16] A.P. Tsai, S. Kameoka, M. Terauchi, United state Patent No. 7592292B2 (2009).

[17] A.P. Tsai, S. Kameoka, M. Terauchi, European Patent No. EP 1666144A1 (2005)

[18] T. Tanabe, S. Kameoka, A.P. Tsai, Catal. Today 111, 153 (2006).

[19] T. Tanabe, S. Kameoka, A.P. Tsai, Appl. Catal. A: General 384, 241 (2010).

[20] T. Tanabe, S. Kameoka, A. Tsai, J. Mater. Sci. 46 , 2242 (2011)

[21] T.P. Yadav, M. Lowe, R. Tamura, R. McGrath, H.R. Sharma, Aperiodic Crystals, Eds.: S. Schmid, R.L. Withers, R. Lifshitz, Springer Science, 2013, p. 275.

[22] T.P. Yadav, N.K. Mukhopadhyay, R.S. Tiwari, O.N. Srivastava, Mat. Sci. Eng. A 393, 366 (2005). 